\title{
A position statement on kidney disease from powdered infant formula-based melamine exposure in Chinese infants
}

\author{
Craig B. Langman • Uri Alon • Julie Ingelfinger • \\ Märta Englund • Jeffrey M. Saland • \\ Michael J. G. Somers • F. Bruder Stapleton • \\ Nelson Orta Sibú • Pierre Cochat • William Wong • \\ Felicia U. Eke • Lisa Satlin • Isidro Salusky
}

Received: 20 December 2008 / Accepted: 22 December 2008 / Published online: 7 February 2009

(C) IPNA 2009

\begin{abstract}
Melamine, a man-made non-nutritive substance containing nitrogen, can falsely elevate measures of protein content in foodstuffs. Several manufacturers of powdered infant formula in China apparently added melamine to raise
\end{abstract}

C. B. Langman

Feinberg School of Medicine,

Northwestern University-Children's Memorial Hospital,

Chicago, IL, USA

U. Alon

Pediatric Nephrology, The Children's Mercy Hospital,

Kansas City, MO, USA

J. Ingelfinger

Pediatric Nephrology, Massachusetts General Hospital,

Boston, MA, USA

\section{Englund}

Sach's Children's Hospital, Karolinska Institutet,

Stockholm, Sweden

M. Englund

Department of Clinical Science and Education, Södersjukhuset,

Stockholm, Sweden

J. M. Saland $\cdot$ L. Satlin

Department of Pediatrics, The Mount Sinai Medical Center,

New York, NY, USA

\section{J. G. Somers}

Harvard Medical School and Children's Hospital Boston,

Boston, MA, USA

\section{F. B. Stapleton}

Department of Pediatrics,

University of Washington School of Medicine

and Seattle Children's Hospital,

Seattle, WA, USA the measured protein content and thereby exposed thousands of infants and young children to very high levels of melamine. Such exposure resulted in cases of acute kidney failure and nephrolithiasis. This Editorial from

N. O. Sibú

Hospital de Niños Insalud/Universidad de Carabobo,

Valencia, Venezuela

P. Cochat

Département de Pédiatrie-Inserm U820,

Centre de Référence des Maladies Rénales Héréditaires,

Hôpital Edouard-Herriot and Université Lyon 1,

Lyon, France

W. Wong

Department of Nephrology, Starship Children's Hospital,

Park Road,

Grafton, Auckland, New Zealand

F. U. Eke

University of Port Harcourt,

Port Harcourt, Nigeria

I. Salusky

Department of Pediatrics,

David Geffen School of Medicine at University of California,

Los Angeles, CA, USA

C. B. Langman $(\triangle)$

Kidney Diseases, Children's Memorial Hospital,

2300 Childrens Plaza \#37,

Chicago, IL 60614, USA

e-mail: c-langman@northwestern.edu 
members of the world-wide Pediatric Nephrology community provides a common-sense approach to the care of infants who may have been exposed to powdered infant formula in 2007-2008.

Keywords Acute kidney failure · Infant nutrition . Nephrolithiasis · Poisoning

\section{Introduction}

Widespread disease in infants and young children resulting from exposure to toxic substances in medication is not uncommon in the modern world [1]. In the latter part of 2008, news reports appeared - and Chinese government authorities confirmed - that some manufacturers had added melamine to powdered infant milk formulas in China from the latter parts of 2007 through most of 2008 in order to increase the apparent protein concentration readings. Subsequently, there has been world wide concern about kidney disease stemming from melamine exposure [2]. This Editorial, written by members of the world-wide Pediatric Nephrology community, was stimulated by a request from the International Pediatric Nephrology Association (IPNA, www.ipna-online.org) and is intended to provide a brief overview of this topic and an approach for physicians who may see affected children (please also see recommendations from the Ministry of Health of China (http://www. moh.gov.cn/) and the Beijing Health Bureau (http://www. bjhb.gov.cn/).

The man-made compound, melamine, $\mathrm{C}_{3} \mathrm{H}_{6} \mathrm{~N}_{6}$, also known as cyanuramide, is a synthetic product that forms

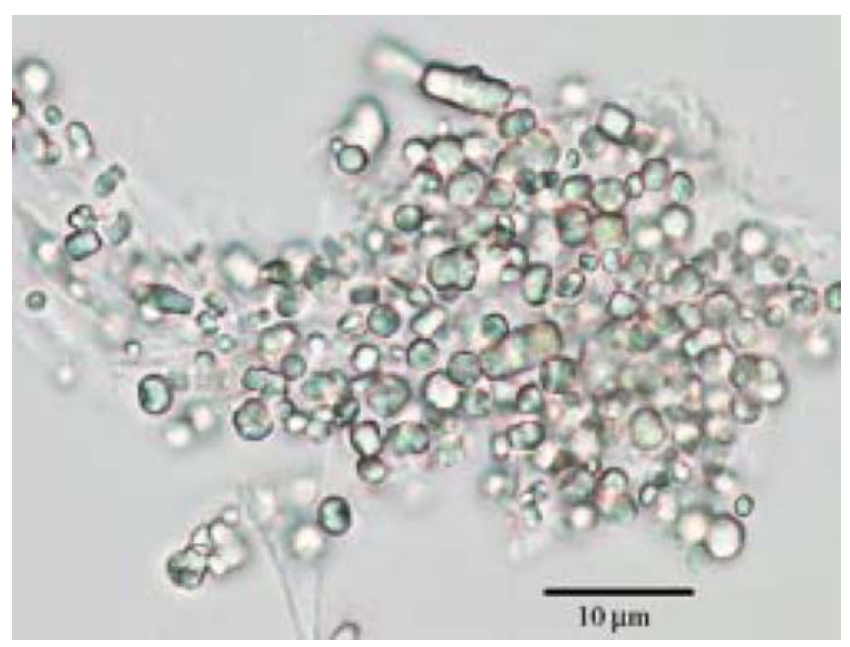

Fig. 1 A unique picture of melamine + cyanuric acid crystals [www. labservices.uoguelph.ca/urgent.cfm] found in the urinary sediment from an affected infant
Table 1 Signs and symptoms reportedly associated with melamine exposure from powdered infant formula in Chinese infants

- Unexplained crying in infants, especially when urinating

- Vomiting

- Unexplained fever secondary to urinary tract infection, or bacteremia secondary to urinary stasis resulting from obstruction

- Macroscopic or microscopic hematuria

- Acute obstructive oligo-anuric kidney failure

- Stones discharged while passing urine

- High blood pressure, edema, elicitable flank pain

resins with formaldehyde. It is used in a variety of products containing resin-based coatings but is not intended for human or animal consumption as food. However, as it contains soluble nitrogen, it has the potential to confound surrogate measures of protein content, such as nitrogen content. Melamine and related substances, such as hexamethylmelamine, were explored as potential anti-cancer agents in the 1960s and 1970s but were abandoned due to toxicity and insufficient benefit. The urinary metabolites recovered after the administration of hexamethylmelamine in phase I studies indicated that the s-triazine ring is very stable and does not undergo cleavage in vivo [3]. Melamine is poorly soluble in water (approx. $6 \mathrm{~g} / \mathrm{L}$ at $37^{\circ} \mathrm{C}$ ) as are its organic and inorganic salts [4].

In experimental murine and rat models, chronic melamine exposure resulted in the production of kidney and bladder stones (urolithiasis) and, possibly, transitional cell carcinoma of the bladder [5]. There appears to be a gender difference in the appearance of stones, at least in experimental animals, with a much greater incidence in males than in females. Chemical analysis of the calculi in experimental animals demonstrated equimolar amounts of melamine and uric acid, accounting overall for $61-81 \%$ of the weight of the recovered stones [6]. Other studies have demonstrated equal parts of melamine and cyanuric acid. Furthermore, stone formation appears to be dose-, threshold-, and concentration-dependent, but whether stone formation may occur with long-term, low-dose exposure settings remains unclear. A study on pet-food melamineassociated kidney disease seen in cats and dogs in the USA in the past 2 years found that the composition of the urinary stones was similar to that noted in experimental rodent models. In these domestic pets, most of the crystal deposition was found to be located in the distal tubule [7]. Additionally, tubulointerstitial nephritis was noted in some affected dogs that came to necropsy [8]. Unique melamine/ cyanuric acid crystals were noted in the urine in some cases (Fig. 1). 
Table 2 Diagnostic criteria for suspecting powdered infant formula-associated melamine kidney disease
Possibly affected children

- Infants from China who were fed with melamine-contaminated powdered infant milk formula in late 2007 or during 2008

- Infants with one or more of the clinical manifestations noted in Table 1

Laboratory test results supporting exposure

- Routine urinalysis that reveals hematuria which is eumorphic

- Abnormalities in kidney function tests that estimate glomerular filtration, such as serum creatinine levels

- Absence of abnormalities in urinary excretion ratio of calcium to creatinine; blood parathyroid hormone levels; levels of hepatic enzymes

Radiographic imaging studies supporting exposure

- Kidney ultrasound demonstrating unilateral or bilateral enlargement, increased echogenicity, normal parenchymal thickness, slight pyelectasis and caliectasis, blunted calyces

- Presence of nephrolithiasis on plain radiograph, ultrasound or computed tomography scan

\section{Melamine and disease in infants in China}

In late September, 2008, the U.S. Food and Drug Administration (FDA) and the World Health Organization (WHO) reported a total of over 54,000 cases of melamineinduced illness, including kidney stones and a number of instances of acute kidney failure, linked to consumption of powdered infant milk formula contaminated with melamine [9]. Based on these reports, there were over 14,000 hospitalizations and at least three confirmed deaths (WHO, 15 October 2008 [2]). Of the children affected, $82 \%$ were younger than 2 years; no cases involved adults, and no cases were associated with liquid infant formula. An investigation conducted within China (General Administration of Quality Supervision, Inspection, and Quarantine of the People's Republic of China) revealed that 22 different companies produced the tainted powdered infant formula and that samples from those formulas contained melamine concentrations that ranged from 0.1 to $2500 \mathrm{ppm}$.

Illness related to melamine-contaminated powdered infant formula was reported from multiple regions of China, including Anhui, Gansu, Henan, Hubei, Hunan, Jiangsu, Jiangxi, Ningxia, Shaanxi, and Shandong provinces. Chinese medical authorities released information that studies on 14 kidney stones had provided sufficient information to allow them to comment on the composition of the stones, which demonstrated the presence of uric acid dihydrate and/or struvite. The stones were not uniformly radio-opaque, but they were easily visualized by ultrasound or computed tomography scans. 'It has also been observed that the stones were rather loose and soft, some of which on copious water drinking, could be passed out as sand and sediments, making the urine slightly cloudy and turbid' [10].

From anecdotal reports currently available, a variety of signs and symptoms have been observed in infants in China affected by the melamine-contaminated infant formula, ranging from nonspecific findings to acute obstructive oligo-anuric kidney failure due to urinary obstruction from melamine-containing stones (Table 1).

\section{Suggested key diagnostic criteria for possible melamine-associated kidney disease}

The key diagnostic criteria that suggest melamine-associated kidney and urinary tract disease include both demographics and supporting clinical and laboratory data. These are detailed in Table 2.
Table 3 Suggested basis for physician assessment of infants suspected of melamine exposure due to the consumption of powdered infant formula
- A complete physical examination, including measurement of blood pressure, assessment of general nutritional status and hydration

- Complete urinalysis (including a microscopic examination of the urine)

- Measurement of creatinine, blood urea nitrogen, and serum electrolytes ("renal function panel") and estimation of glomerular filtration rate

- Performance of an abdominal ultrasound that includes the kidneys and the urinary bladder

- Note that the preferable ultrasound examination should include an ultrasound exam of the urinary system

- If necessary, an abdominal computed tomography scan (we do not suggest intravenous urography and the latter should absolutely not to be used in the case of anuria or renal failure)

- Radionuclide renal scans may be considered to evaluate renal function if there is a question of renal dysfunction

- Referral to a pediatric nephrologist or pediatric urologist is suggested for children with suggestive signs and symptoms or who have abnormal kidney function tests, and/or abnormal ultrasound findings 


\section{Recommendation for physicians for evaluation of infants possibly exposed to melamine from powdered infant formula}

We believe that recommendations for assessment are best based on a common-sense approach until more substantive data are available in the medical literature. Steps for assessment are noted in Table 3.

- In our opinion, asymptomatic, thriving infants have little to no likelihood of developing powdered infant formula-based melamine-associated kidney disease. Therefore, testing should not be performed on asymptomatic infants who may have been living in the geographic areas of China noted to have melamineassociated kidney disease found in late 2007 or during 2008.

- Infants from China who may have been exposed to powdered formula and who have unexplained fussiness, unexplained vomiting, renal colic, macroscopic hematuria, stone passage, urinary tract infection, hypertension, edema, and/or oliguria should undergo the screening and management noted in Table 3.

As more data become available, these present suggestions may evolve. It is reassuring that new cases of melamine-associated acute renal failure do not seem to be appearing. Nonetheless, the long-term sequelae of these exposures are unknown.

\section{References}

1. Bogdanich W (2007) "As FDA Tracked Poisoned Drugs, A Winding Trail Went Cold in China", New York Times June 17, 2007

2. Xin H, Stone R (2008) Chinese probe unmasks high-tech adulteration with melamine. Science 322:1310-11

3. Ames MM, Richardson RL, Kovach JS, Moertel CG, O'Connell MJ (1990) Phase I and clinical pharmacological evaluation of a parenteral hexamethylmelamine formulation. Cancer Res 50:206210

4. Crews GM, Ripperger W, Kersebohm DB, Güthner T, Mertschenk B (2008) Melamine and guanamines. In: Wiley-VEH (ed) Ullmann's encyclopedia of industrial chemistry. Wiley, Hoboken

5. Melnick RL, Boorman GA, Haseman JK, Montali RJ, Huff J (1984) Urolithiasis and bladder carcinogenicity of melamine in rodents. Toxicol Appl Pharmacol 72:292-303

6. Ogasawara H, Imaida K, Ishiwata H, Toyoda K, Kawanishi T, Uneyama C, Hayashi S, Takahashi M, Hayashi Y (1995) Urinary bladder carcinogenesis induced by melamine in F344 rats: correlation between carcinogenicity and urolith formation. Carcinogenesis 16:2773-2777

7. Brown CA, Jeong KS, Poppenga RH, Puschner B, Miller DM, Ellis AE, Kang KI, Sum S, Cistola AM, Brown SA (2007) Outbreaks of renal failure associated with melamine and cyanuric acid in dogs and cats in 2004 and 2007. J Vet Diagn Invest 19:525-531

8. Thompson ME, Lewin-Smith MR, Kalasinsky VF, Pizzolato KM, Fleetwood ML, McElhaney MR, Johnson TO (2008) Characterization of melamine-containing and Calcium Oxalate Crystals in three dogs with suspected pet-food induced nephrotoxicosis. Vet Pathol 45:417-426

9. World Health Organization (2008) Melamine-contaminated powdered infant formula in China in 2008. Available at: http://www.who.int/csr/ don/2008_09_29a/en/index.html

10. Wong SN, Chiu MC (2008) The scare of melamine tainted milk products. HK J Paediatr (new series) 13:230-234 